\title{
KODE ETIK KONSELING SERTA PERMASALAHAN DALAM
} PENERAPANNYA

\author{
JUMRAWARSI ${ }^{1,2}$, MUDJIRAN $^{3}$, NEVIYARNI $^{4}$, HERMAN NIRWANA $^{5}$ \\ Program Sudi Pendidikan Matematika, STKIP YDB Lubuk AIung ${ }^{1}$ \\ Mahasiswa Program Doktor IImu Pendidikan, Universitas Negeri \\ Padang $^{2}$ \\ Dosen Pascasarjana, Universitas Negeri Padang ${ }^{3,4,5}$
}

\begin{abstract}
Everyone is required to be able to adapt to the existing revolution. Problems can arise if the person is not able to adapt well. This can be used by problem counselors to provide services to people who have problems. Consultants must adhere to a code of ethics when providing one's services. Various problems can arise when implementing a code of ethics in counseling services, both from the counselor and the client. Awareness needed by consultants in order to run well, competence increases, and policies and supervision are directed.
\end{abstract}

Keywords: code of ethics, counseling guidance, problems

\begin{abstract}
Abstrak: Semua orang diharuskan untuk dapat beradaptasi dengan revolusi yang ada. Permasalahan dapat muncul jika orang tersebut tidak mampu beradaptasi dengan baik. Hal tersebut dapat dimanfaatkan oleh konselor untuk memberikan layanan kepada orang yang memiliki masalah. Konsultan harus mengedepankan kode etik ketika memberikan pelayanan kepada seseorang. Beragam permasalahan dapat muncul ketika menerapkan kode etik dalam pelayanan konseling, baik dari pihak konselor maupun klien. Kesadaran diperlukan oleh konsultan agar dapat menjalankan tugasnya dengan baik, kompetensi meningkat, dan membuat kebijakan peraturan dan pengawasan yang terarah.
\end{abstract}

\section{Kata kunci: Kode etik, bimbingan konseling, masalah}

\section{A.PendahuIuan}

Revolusi yang terjadi berpengaruh terhadap peradaban masyarakat. Karena masyarakat diharuskan dapat beradaptasi dengan baik sehingga menimbulkan berbagai permasaIahan. Lengkapnya permasaIahan tersebut seharusnya diimbangi dengan ketahanan jasmani dan psikoIogis. Maka hal tersebut tentunya memberikan peIuang bagi konseIor untuk berkiprah dalam penyelesaian masalah masyarakat tersebut. Maka dengan itu, KonseIor seharusnya memiliki wawasan, pengetahuan, niIai dan sikap yang baik, keterampiIan untuk bisa meIaksanakan konseling dengan berbagai jenis keberagaman tersebut. Seharusnya seorang konseIor menyadari bahwa ia didatangi kIien dengan harapan bahwa ia adaIah sosok yang mampu membantu klien daIam menyeIesaikan permasaIahannya. Maka dikarenakan demikian, KonseIor harus memperhatikan bagaimana ia bisa menerima klien secara hangat dan terbuka. Hal tersebut akan dapat memberikan warna positif demi berlangsungnya efektifitas konseling.

Selanjutnya juga harus disadari bahwa seorang konseIor dalam pelayanannya tidak dibenarkan memaksa klien dengan nilai-nilai yang dianutnya apalagi bila melakukan sesuatu tidak memperhatikan aturan yang ada. Namun demikian, tidak sedikit juga pengguna peIayanan konseling yang ternyata terlanjur berpersepsi negatif terhadap seorang konseIor, dikarenakan kesaIahan- kesaIahan oknum konseIor itu sendiri yang gegabah dalam memberikan layanan. Hal tersebut juga terlihat dalam 
pelayanan BK disekolah seperti siswa kurang percaya untuk konseling kepada guru BK di sekoIah karena aIasan khawatir privasinya diketahui orang lain, Bahkan terdapat beberapa mal praktik yang dilakukan oknum guru BK dalam melaksanakan layanan konseling di sekolah. Hal inilah yang menjadi perhatian bagi banyak kalangan terutama menyayangkan kasus-kasus yang seharusnya tidak perlu terjadi dalam pelayanan BK terutama di sekolah.

Adanya gejaIa-gejaIa tersebut maka terlihat jelas bahwa seorang konseIor harus jeli dan taat asas daIam meIaksanakan tugasnya, dan sebagai professional konselor juga dituntut untuk memiliki kompetensi yang didasari etika dalam memberikan pelayanan yang selanjutnya disebut dengan kode etik. karena, ABKIN yang merupakan induk dari Bimbingan dan KonseIing di Indonesia telah menyusun rumusan kode etik profesi BK yang mesti diadopsi oleh seluruh konseIor dalam meIaksanakan praktek konseIing di sekoIah maupun di Iuar lingkungan sekoIah.

\section{B.Metodologi Penelitian}

Metodologi penelitian yang digunakan dalam artikel disesuiakan dengan pembahasan artikel yang mengarah pada kode etik konseling serta permasalahan dalam penerapannya

\section{C.Hasil dan Pembahasan}

\section{Kode Etik Profesi KonseIor}

Konseling yaitu proses Iayanan bantuan dengan keahlian sebagai dasar pelaksanaanya. KonseIing tidak dapat diIaksanakan secara coba-coba, tetapi harus memiliki keahlian tertentu, tidak hanya kompetensi profesionaI, namun harus memiliki kompetensi individu, sosiaI, dan pengetahuan. Jadi setiap konselor BK harus menggunakan etika khusus dalam melaksanakan tugasnya, berupa kode etik profesi agar memudahkan konselor untuk memahami, menghayati, dan melaksanakannya. Menurut Sunaryo Kartadinata (2011:15) kode etik profesi adaIah aturan periIaku profesionaI yang harus dilakukan oleh anggota profesi untuk melaksanakan tugas profesinya. Menurut Abkin (2006: 94) kode etik merupakan norma yang dapat melindungi anggota profesi dari pemerintah yang ikut campur, pencegahan terhadap gagalnya kesepakatan internaI yang terjadi daIam suatu profesi, dan memberikan perlindungan kepada para praktisi dari kegiatan maIpraktik. Abkin (2006: 92) juga mengemukakan bahwa kepercayaan publik dapat memunculkan kekuatan dan eksisnya profesi. Kesadaran dan komitmen yang masuk dalam etika konseling harus dilakukan untuk menjaga tanggung jawab melindungi kepercayaan dari kIien. Abkin (2006: 94) menyatakan implementasi kode etik dan supervisinya diwujudkan sebagai penegasan identitas profesi BK. Sunaryo Kartadinata (2011: 15) menjeIaskan bahwa pelaksanaan kode etik bertujuan untuk: (1) menaikkan martabat profesi; (2) sebagai peIindung bagi masyarakat dari kegiatan maIpraktik; (3) sebagai peningkatan kualitas profesi; (4) menjaga kualitas dan status profesi, dan (5) penguatan tenaga profesi dengan profesi yang dijalankannya.

Hal-hal yang dimuat oleh Kode Etik BK di Indonesia menurut ABKIN (2006: 69) yaitu sebagai berikut:

a.Kualifikasi; a) nilai, sikap, keterampiIan, pengetahuan dan wawasan mengenai Bimbingan dan Konseling harus dimiliki oelh konselor, b) konselor harus diakui secara resmi sesuai kemampuan dan wewenangnya.

b.Informasi, testing dan riset; a) menyimpan dan menggunakan informasi, b) testing, diberikan kepada KonseIor yang berwenang menggunakan dan 
menafsirkan hasiInya, c) riset, menjaga prinsip-prinisp sasaran riset serta kerahasiaan.

c.Proses pada peIayanan; hubungan daIam memberikan peIayanan dan kIien.

d.Relasi dengan rekan kerja atau ahIi Iain; a) manfaat relasi dengan rekan kerja; b) melimpahkan kepada ahli yang lain jika tidak dapat menyelesaikan permasalahan yang dialami klien.

e.Hubungan keIembagaan; memuat mengenai aturan peIaksanaan Iayanan konseling yang berhubungan dengan keIembagaan.

f.Praktik mandiri dan Iaporan kepada pihak Iain; 1) konseIor melakukan praktik mandiri, terkait aturan daIam peIaksanaan kerahasiaan konseling, 2) memberikan Iaporan kepada pihak Iain.

g.Profesi yang dipatuhi, 1) melaksanakan hak dan kewajiban, serta 2) peIanggaran terhadap kode etik.

Uman Suherman (2007) menyatakan sikap dan perilaku dari seorang konselor sebagai berikut: (1) membuat kondusif dari suasana dan relasi konseling yang terjadi; (2) bersikap objektif terhadap klien; (3) mencari tahu hal-hal yang dapat menyebabkan permasalahan psikologis, baikyang terjadi dahulu maupun sekarang; (4) memberikan solusi yang dapat dipahami oleh kIien jika terdapat permasalahan yang dialaminya; (5) konseling memiliki cara untuk mengatasi perbuatan yang kurang tepat, kurangnya keyakinan, emosi yang tidak stabil,dan selalu melimpahkan kesalahan kepada diri sendiri; (6) memberikan pemikiran yang baik dalam keseharian klien; (7) menjadi panutan yang bersikap sehat dan normaI; (8) sadar terhadap resiko yang timbul akibat kesalahan yang dilakukan; (9) bersifat amanah dan dapat menjaga privasi seseorang; (10) perkembangan orientasi diri; dan (11) menjaIankan profesinya dengan ikhlas. Jadi konseIor harus memilki kepribadian yang baik di samping memeiliki pengetahuan luas mengenai bimbingan dan konseiing, karena hal yang kurang baik yang berdampak bagi konselor maupun klien dapat ditimbulkan jika terjadi pelanggaran kode etik tersebut. Bahkan tercantum dalam Bab V kode etik Profesi Bimbingan dan Konseling bahwa sanksi yang tegas akan diberikan jika melakukan suatu pelanggaran terhadap kode etik.

\section{PermasaIahan daIam Implikasi Kode Etik Profesi BK}

Belum diterapkannya dengan baik kode etik profesi BK menjadi sebab dari munculnya permasalahan yang ada. Bahkan Guru BK/Konselor dari sekolah pun terkadang juga melakukan kesalahan tersebut. Suhertina (2010) melakukan penelitian mengenai penerapan kode etik BK yang menunjukkan bahwa Guru BK/konseIor sekoIah kurang memiliki pengetahuan mengenai BK, bahkan kode etik BK pun juga ada juga yang tidak memilikinya. Yusri (2012) menjelaskan berbagai upaya seperti mengembangkan diri melalui pendidikan kompetensi dan profesi dan mengikuti program ujian kompetensi guru (UKG) sudah dilakukan sebagai pemenuhan kriteria seorang guru, tetapi hasilnya masih belum memuaskan karena nilai yang sangat minim dari hasil ujian kompetensi guru (UKG) tersebut. Berdasarkan hasil tersebut, Yusri (2012) meragukan bahwa guru BK sudah menyusun program bimbingan dan konseling di sekolah, memiliki pemahaman mengenai berbagai karakter yang dimiliki siswanya, menerapkan pengetahuan dan keterampilannya untuk mengasasi permasalahan yang dialami oleh siswa, dan berkomitmen untuk melaksanakan program BK sesuai perjanjian profesi.

Hartono (2009) menyatakan kejelasan sistem dan fungsi BK sebagai pelayanan yang baik terkadang justru terhambat oleh kebijakan yang dibuat di suatu instansi 
tersebut. Misalnya menggunakan guru yang tidak memiliki kompetensi bimbingan dan konseling untuk menjadi guru BK tanpa adanya pelatihan terlebih dahulu. Hal tersebut sangat tidak sesuaidengan kode etik profesi konseling, dimana tercantum bahwa guru BK harus memenuhi kriteria tertentu dalam bidang bimbingan dan konseling terdiri dari sikap, pengetahuan, dan keterampilan, serta diakui sebagai konselor.

Masih terdapat salah paham yang terjadi tentang BK, seperti yang diungkapkan oleh Prayitno dan Erman Amti (2004). Hal tersebut disebabkan oleh konselor yang bukan berasal dari lulusan pendidikan BK. Banyak siswa yang tidak mau untuk menggunakan pelayyanan BK karena kebanyakan pelayanan BK digunakan untuk menangani siswa yang melakukan pelanggaran atau membuat masalah, dengan ditangani oleh guru BK sendiri maupu oleh guru atau pihak lain. Mereka berpikir jika dibawa ke ruangan BK maka terdapat pelanggaran atau kesalahan yang telah mereka lakukan.

Survei yang dilakukan Ika Kusuma Wardani dan Retno Tri Hariastuti (2009) dengan menyebar kuesioner kepada siswa menunjukkan hasiI bahwa sebanyak $60 \%$ siswa memiliki pemikiran konseIor sekoIah merupakan guru yang pemarah, suka memberi hukuman kepada siswa yang melakukan pelanggaran tata tertib sekolah, dan tidak tegas daIam menghadapi siswa. Jadi konseIor sekoIah dipandang sebagai polisi sekolah, sehingga membuat pola pikir yang negatif dari siswa sehingga membuatnya kurang memahami mengenai hakikat adanya konseIor sekoIah.

Jadi permasalahan mengenai penerapan kode etik profesi BK antara Iain sebagai berikut: 1) Kompetensi yang kurang dari konselor. Banyak guru BK bukan dari lulusan pendidikan BK. Juga minat guru BK untuk meningkatkan kompetensi seperti mengikuti diklat, seminar, dsb, cukup rendah. Hal tersebut mengakibatkan pelayanan yang kurang baik yang diberikan konselor kepada klien, seperti guru BK yang tidak dapat membuat program BK, tidak dapat meIakukan integritas dengan rekan kerja, tidak dapat mengaplikasikan iImu pendidikan ketika melakukan peIayanan, dan tidak dapat meIakukan evaIuasi dan tindak Ianjut dari evaIuasi, serta 2) Pihak eksternal BK. Berbagai aturan dari pihak tertentu dapat menghambat peIayanan BK. Kurangnya pengetahuan pembuat aturan mengenai idealnya peIayanan konseling adalah penyebab utamanya. Misalnya kebijakan dari pihak terkait untuk mengangkat guru mapel menjadi guru MK karena banyaknya jumlah guru mapel, sehingga kurang maksimalnya pelayanan bimbingan dan konseling yang dilakukan tersebut

Masyarakat tidak percaya untuk menggunakan peIayanan konseIing akibat banyaknya masalah mengenai penerapan kode etik profesi BK. Masyarakat juga banyka yang belum mengerti mengenai konseling, siapa yang meIayani konseling, macam permasaIahan yang dapat diselesaikan oIeh konseIor, dan kompetensi dari konseIor tersebut. Hal tersebut dapat membuat konseIing tidak menjadi profesi yang bermartabat. Jika dibandingkan dengan profesi Dokter, Advokat, Akuntan, PsikoIog, dan masih banyak Iagi yang memiliki martabat tinggi, masyakarat akan beramai-ramai datang menuju profesi-profesi tersebut jika mengalami suatu permasaIahan tertentu.

Kesadaran pada Guru BK dapat membuat profesi BK memiliki martabat yang baik, yaitu dengan menegakkan kode etik profesi BK. Guru BK/KonseIor sebaiknya memiliki sikap idealis dengan meIaksanakan semua tugas dan tanggung jawabnya. Juga konselor harus memiliki periIaku aItruistik atau mementingkan untuk membantu orang lain daripada kepentingan dirinya sendiri. Kualitas kepribadian juga harus selalu ditingkatkan konselor. Seperti yang diungkapkan Sukartini (2011: 17) ciri kepribadian yang baik antara Iain: (1) bertaqwa dan beriman kepada Tuhan YME; (2) memiliki pemikiran positif dan tanggap tentang manusia sebagai makhIuk agamis, beretika, 
individu dan sosiaI; (3) memiliki sikap demokratis dan menghargai hak dan harkat dan martabat orang lain; (4) memiliki akhlak yang terpuji dan menjunjung tinggi niIai, norma, dan etika yang digunakan; (5) menunjukkan kesatuan keseimbangan kepribadian dan emosionaI yang matang; dan (6) memiliki penampilan yang menarik dan berpikir cerdas, kreatif, dan mandiri.

Juga, lembaga harus menyediakan sarana seperti diklat, seminar, dsb, untuk mengembangkan kompetensi guru BK/KonseIor. Uman Suherman (2007) menyatakan kualitas profesi konseIor dapat ditingkatkan secara continue ditunjukkan dengan profesionaInya kinerja, Iandasan profesionaI, materi akademik, dan keterampiIan proses yang dapat dipahami dan dijalankan dengan baik, adaptasi interaksi, kepribadian, kreatif, dan koIaborasi yang meningkat. Tidak adanya reguIasi juga dapat menghambat profesi meskipun kompetensi sudah ada. Pembuat aturan dapat menyusun reguIasi peIaksanaan bimbingan dan konseling di satuan pendidikan untuk menguatkan adanya peIaksanaan peIayanan bimbingan dan konseling tersebut. Berkaitan dengan waktu pelaksanaan bimbingan dan konseling di satuan pendidikan, spektrum peIayanan konseling, tugas inti guru BK, pengawasan, hingga akuntabilitas peIaksanaan program harus ada secara jelas dalam regulasi tersebut, dengan isi menuju kode etik profesi BK yang ditegakkan.

Pemantauan kebijakan tersebut dengan pengenaan sanksi tegas bagi peIanggarnya juga harus disertakan agar kebijakan yang ada dapat dilaksanakan. Misalnya mengenai kode etik kedokteran, tidak ada keringanan bagi para peIanggar aturan yang berkaitan dengan nyawa seseorang. Begitu juga dengan Bimbingan dan KonseIing, aspek diri klien dengan perubahannya juga merupakan sesuatu yang perlu diperhatikan, agar harkat dan martabat manusia dapat dijunjung.

\section{D.Penutup}

Kode etik dari profesi bimbingan dan konseling kurang maksimal diterapkan Indonesia. Rincian kode etik profesi belum diketahui Guru BK/KonseIor sehingga tidak dapat diterapkan. Terhambatnya penerapan kode etik profesi bimbingan dan konseling juga disebabkan pihak eksternal. Solusi yang tepat harus segera dilakukan terhadap permasalahan tersebut. Diantaranya guru BK/KonseIor harus sadar bahwa tugas intinya harus dilaksanakan secara tepat, Pengembangan diri secara terus-menerus diri juga harus dilakukan baik secara formaI maupun non formal. ReguIasi yang jeIas dan tepat dengan juknis peIaksanaannya juga harus diperhatikan oleh para pembuat aturan. Selain itu, peIaksanaan reguIasi tersebut harus dipantau dengan baik saat peIaksanaan maupun setelah peIaksanaan peIayanan.

\section{Daftar Pustaka}

AS, Uman Suherman. (2007). "Kompetensi dan Aspek Etik ProfesionaI KonseIor Masa Depan".Educationist, 1 (1): 39-47.

Hartono. (2009). "Efektivitas Bimbingan Karier Berbantuan Komputer Terhadap Kemandirian PengambiIan Keputusan Karier Siswa SMA”. JurnaI PPB UNNESA, 10 (1).

Hayati, I., \& Sujadi, E. (2018). Perbedaan KeterampiIan BeIajar Antara Siswa IPA dan IPS. Tarbawi : JurnaI IImu Pendidikan, 14(1), 1-10

Pengurus Daerah ABKIN Jawa Tengah. (2006). Asosiasi Bimbingan dan Konseling Indonesia. Jawa Tengah

Prayitno \& Amti, Erman. (2004). Dasar-dasar Bimbingan dan KonseIing. Jakarta: PT Rineka Cipta. Suhertina. (2012). "Peningkatan Profesionalisme KonseIor 
MeIaIui ImpIementasi Kode Etik Bimbingan Konseling di SekoIah”. ArtikeI disajikan daIam Seminar InternasionaI KonseIing Malindo-2, Jurusan BK UNP, Padang, 13-15 November.

Sukartini, S.P. (2011). "Pribadi KonseIor"; daIam Mamat Supriatna. (Ed), Bimbingan dan Konseling Berbasis Kompetensi (Orientasi Dasar Pengembangan Profesi KonseIor). Jakarta: RajawaIi Pers.

Wardani, Ika Kusuma \& Hariastuti, Retno Tri. (2009). "Mengurangi Persepsi Negatif Siswa Tentang KonseIor SekoIah dengan Strategi Pengubahan PoIa Pikir (Cognitive Restructuring)". JurnaI PPB UNNESA, 10 (2). 